\title{
RECENSIÓN
}

\section{Daniel Innerarity, Política para perplejos, Barcelona: Galaxia Gutenberg, 2018 (192 págs.)}

Los intelectuales siempre han deseado captar a través de su obra la pulsión de su tiempo, con la finalidad de interpretarla, y permitir a los lectores entender su contexto existencial. El correcto enfoque inicial al plantear los problemas por parte de los intelectuales orientaría también hacia una solución adecuada. Esta obra cumple en parte con estas premisas, al profundizar con agudeza y claridad en los graves problemas que atenazan nuestras sociedades desde diversas perspectivas, combinando análisis político, social, cultural y filosófico; sin embargo, la diferencia con otras contribuciones similares radica en la sinceridad y humildad de esta aportación. Prácticamente toda la obra gira en torno al reconocimiento recurrente y pertinente de que lo definitorio de nuestro contexto actual es la complejidad de los escenarios locales y globales interconectados, obligando a poner el acento en la detección de los síntomas de las disfuncionalidades sociopolíticas y en la profundidad que requieren los análisis de los problemas a los que nos enfrentamos.

El término perplejidad se encuentra muy acertadamente situado en el título porque supone destacar la incertidumbre actual de carácter existencial y de dimensiones colosales que atraviesa a las sociedades humanas en las relaciones que establecen consigo mismas, pero también con un ecosistema imprevisible como consecuencia de la propia acción del ser humano. Este contexto deviene en paradójico en la medida en que las sociedades humanas se encuentran abocadas a esforzarse con la finalidad de conocer el futuro para gestionar una complejidad irreductible, pero es también esa misma complejidad, al mismo tiempo, la que impide identificar y ofrecer respuesta a los desafíos de ese futuro. Para el autor, lo que incomoda es no ser capaces de identificar la fuente del malestar, ni tampoco a quién se puede atribuir la responsabilidad de mitigarlo.

En el ámbito de lo político se identifica con cierta claridad el desconcierto en relación con lo que defienden los conservadores y los progresistas, partiendo de una dificultad inicial vinculada con qué es lo que desean realmente conservar unos y cambiar otros. Somos herederos de "realidades indiscutibles", y eso supone una desventaja sustancial para comprender la realidad actual. La búsqueda de atajos impulsa a los individuos a 
través de vías que contribuyen a alejarlos de un enfoque más comprometido con la comprensión realmente crítica de lo que sucede, más aún cuando se genera una inquietante cercanía entre pensamiento crítico y conspirativo. Resulta muy interesante la relevancia que el autor atribuye al poco sofisticado concepto de chapuza como respuesta improvisada y poco reflexionada, pero generalizada en la solución a todos los problemas que parecen requerir aportaciones maduradas y mesuradas. Supone el reconocimiento implícito del desbordamiento que produce una realidad imposible de ser comprendida y gestionada. La "posverdad" en este contexto es entendida como un discurso que distrae de la complejidad de un mundo incomprensible.

Al mismo tiempo, nuestras sociedades se caracterizan por la creciente individualización de los modos de vida y de los sujetos. Ello desemboca en sociedades que ya no responden a lógicas únicas o convergentes, a lo que además está contribuyendo internet a través de la posibilidad de que cada sujeto se represente a sí mismo. De esta manera surge otro problema: ¿cómo categorizar a las personas sin subsumirlas en grupos sociales?

Una de las reflexiones recurrentes en esta obra es la importancia de la gestión de las pasiones y su superposición al conocimiento, apostando el autor claramente por la inteligencia frente a la emoción. La banalización de la política convirtiéndola en mera gestión tecnocrática y en actividad publicitaria degenera en un lenguaje elemental que solo transmite furia. En este contexto, se puede llegar a pensar que, al disponer de amplia información a través de los nuevos medios, la ciudadanía puede quedar exonerada de desarrollar reflexiones personales. En cierta manera la actitud frente al terrorismo sería una expresión clara del desconcierto ante lo que se intuye por la avalancha de datos e interpretación, pero no se sabe, básicamente porque no se conoce con precisión lo que se está buscando. La consecuencia es una limitación ostensible de las libertades a muy diferentes niveles, incrementando la ansiedad, la sospecha y realimentando los argumentos en favor de la vigilancia.

Los nuevos conflictos en nuestras sociedades, según el autor, se explican por tres factores: la desintegración social, el contagio de un mundo interdependiente y la desigualdad como fenómeno global. Desde esta perspectiva, y resaltando la dimensión social, se puede afirmar, según Bertrand Badie, que es más preciso aludir a lo intersocial que a lo internacional. En este escenario, se debería exigir más inteligencia que emoción, por la perspectiva reflexiva requerida donde surge la necesidad de desarrollar una mirada que no solamente culpabilice a los demás, sino que asuma las propias responsabilidades. Parafraseando a Ulrich Beck, las sociedades contemporáneas producen lo que no desean. 
La parte más importante del libro está dedicada a los problemas del funcionamiento de la democracia. Para el autor resulta fundamental que la base de la reflexión sobre la democracia sea la igualdad y no el orden ni el cambio. Lo procedimental es también sustantivo en la definición de las democracias al criticar los referendos porque suponen empoderar momentáneamente a las personas, pero permiten a los gobernantes gestionar el proceso posterior, muy complejo, donde se ordenan las relaciones surgidas de ese instante democrático que ha quedado atrás. Innerarity aporta una reflexión muy clásica respecto a las implicaciones últimas de la democracia, pero también muy olvidadas acerca de su real significado cuando destaca que el poder democrático es de "tránsito e inestable”, pero esencialmente vacío. Su sofisticado enfoque va más allá al destacar la imprecisión de la atribución del poder a unos actores frente a su ausencia en otros, porque esta distinción irreal, radical y binaria impide observar cómo el poder se encuentra mucho más difuminado de lo que parece.

La reflexión que plantea sobre las mujeres en la política constituye una vía más hacia el incremento de la complejidad en nuestras sociedades. Frente al avance de la mujer en todos los ámbitos sociopolíticos, sin embargo, no se le permite alejarse de su condición al asignársele unas características específicas. Así, el autor destaca que la incorporación de la mujer al mundo de la política no debería realizarse en función de su capacidad para actuar en cuanto que tales, sino con la finalidad de corregir un desequilibrio ancestral que impide a una parte de la humanidad ocupar el lugar que le corresponde.

Cuando analiza las confrontaciones ideológicas atribuye ciertos rasgos a la derecha al resaltar ésta la inevitabilidad y simplificación de los procesos sociales. También parece sentirse más cómoda ante la incertidumbre, puesto que lo que importa es que las cosas funcionen. Mientras que la izquierda sitúa el acento en la configurabilidad y complejidad de dichos procesos e interpretándolos con más dificultad, aspecto este último sobre el que el autor no profundiza con claridad. Esta dinámica permite a la derecha resultar más comprensible a una audiencia amplia en busca de explicaciones simples y fácilmente popularizables. De la misma manera el capitalismo actúa como un reductor de complejidad. La ciencia y la tecnología vendrían en auxilio de esta simplificación.

Lo que se pone de manifiesto es que el futuro se aleja de los enfoques clásicos de izquierda y derecha en cuanto al debate sobre la intervención del Estado, lo que obligará a centrarse en la necesidad de gestionar lo mixto, la complejidad y lo heterogéneo. Resulta de especial interés la crítica que realiza a las élites progresistas de carácter cosmopolita que no han visto los efectos más disfuncionales de la diversidad en aquellas comunidades que las padecen en su cotidianidad, porque los intereses de dichas élites no estaban en juego. Probablemente la reconciliación deba venir de la mano, tanto de la redistribución como del reconocimiento. Lo peor es que se asume que la función de la 
política no ha cambiado, por lo que se entiende simplemente que es necesario buscar otras soluciones.

Siguiendo esta línea argumental, se entiende que la relevancia que atribuye el autor a la gobernanza es consecuencia de la capacidad que posee este concepto para trascender el enfoque clásico de la política. Los límites de los Estados se han difuminado y la complejidad ha emergido en un entorno interdependiente. Así, la gobernanza permite resignificar la política y darle un nuevo contenido en un contexto donde los clásicos parámetros conceptuales y territoriales del ejercicio del poder carecen de sentido.

Abundando en su forma de entender el buen gobierno, se destaca la necesidad de superar la acción política como un acto heroico de individuos para atribuir su responsabilidad a un sistema inteligente. Estos deben ser lo sufrientemente precisos y equilibrados como para que cualquiera pueda gobernar. Un sistema democrático debe establecer principalmente límites y es también donde debe reflejarse la inteligencia colectiva, es decir, debe permitir el ejercicio de la voluntad de los gobernantes, limitando la arbitrariedad. Se trata de poner límites al ejercicio del poder sin impedir el progreso. Son contextos en los que la negociación y la confianza son necesarios. Resulta inevitable situar estos comentarios frente a la realidad actual del auge del populismo. Lo cierto es que las dinámicas emergentes apuntan en un sentido contrario, hacia la desconfianza e incapacidad para generar espacios de negociación.

El autor siempre ha tendido a prestar una particular atención a las reflexiones en torno al futuro de nuestras sociedades y la necesidad de realizar un esfuerzo de aproximación, a pesar de las crecientes dificultades derivadas de la complejidad. Pero, precisamente, y debido a esa complejidad que se atisba en este insondable futuro, es necesario realizar esfuerzos suplementarios para comprenderlo. La particularidad del contexto actual radica en que ese mundo cambiante es sobre el que la actual humanidad está actuando y resulta muy difícil discernir qué está cambiando por la voluntad de las sociedades humanas o como consecuencia de la propia evolución del sistema. Daniel Innerarity desconfía de la capacidad de iniciativa del ser humano para cambiar el mundo debido a las chapuzas e improvisaciones que definen su acción donde la previsión y planificación se encuentran ausentes. Para que esta inercia cambiara sería necesario que lo lejano y latente incrementara su importancia frente a lo inmediato y lo visible.

En definitiva, esta obra ofrece una serie de respuestas fundamentales que permiten al estudioso o lector plantearse cuestiones o preguntas de forma ordenada, facilitando la observación al mismo tiempo del abismo que se abre ante nuestras sociedades en relación al incierto futuro. No aporta muchas respuestas concretas, pero sí enfoques y miradas novedosas que permiten aproximaciones a numerosos problemas que definirán nuestro porvenir. Y para lo que es necesario plantear las preguntas correctas. Pero por 
ahora, tal y como afirmara Malcom Gladwell, "aquí quien no esté confundido es que no se entera de nada de lo que está pasando".

Óscar Jaime-Jiménez

Universidad Nacional de Educación a Distancia (UNED), Madrid, España ojaime@poli.uned.es 